\section{Fluid balance in critically ill neonates - ways to improve it}

\author{
DANIJELA MILANOVIC • MOJCA GROSELJ-GRENC
}

\author{
DANIJELA MILANOVIC $(\bowtie) \bullet$ \\ MOJCA GROSELJ-GRENC \\ Department of Paediatric Surgery \\ and Intensive Care \\ University Medical Centre \\ Bohoriceva 20, 1525 Ljubljana, Slovenia \\ Phone: +38615224829 \\ Fax: +38614301714 \\ E-mail: danijela.milanovic@kclj.si
}

\begin{abstract}
Fluid balance is an essential element of intensive care in critically ill neonates. Fluid and electrolyte management is carried out by constant and precise assessment of total fluid intake and output, frequent laboratory monitoring and fluid balance documenting. Accurate continuous and controlled intravenous fluid and drug administration via infusion pumps is crucial. One of the greatest "costs" of fluid and electrolyte status monitoring in critically ill neonates is the volume of blood required for its achievement. A significant volume of blood is required for laboratory testing and increases the need for red blood cell transfusions. In our retrospective observational study we evaluated the fluid balance in 30 critically ill neonates admitted to a level III multidisciplinary neonatal and paediatric intensive care unit (ICU) at the University Medical Centre Ljubljana (UMCL), between September 2011 and January 2012. The information generated by this study provided a basis for the improvement of existing management of fluid balance in critically ill neonates.
\end{abstract}

Key words: fluid balance, critically ill neonate, surgical, non-surgical

\section{Introduction}

Despite advances in the management of critically ill neonates, fluid balance, together with thermal regulation and oxygenation, remains a central feature of modern supportive neonatal intensive care. (1) Fluid balance is a term used to describe the balance of intake and output of fluids by the patient, allowing metabolic processes to run properly. Inadequate administration of fluids can resultinhypovolaemia, hyperosmolarity, metabolic abnormalities and renal failure. In near term and term neonates excess fluid administration results in generalized oedema and abnormalities of pulmonary function. (2)

The volume of fluids administered to critically ill neonates is usually calculated using a weight-based formula and depends on gestational age, post-birth age and the patient's clinical status. The volume of fluid requirements is a sum of maintenance fluid, deficit needs and ongoing losses (e.g. diarrhoea, ostomy or chest tube drainage). (1) It is essential that accurate hourly records are kept of all fluid intake (intravenous solutions, drugs and flushing solutions) and of fluid output (blood samples, body fluid aspirations, urine, stool, vomit or other fluid drainage) to maintain optimal fluid balance. (3)

Umbilical artery and venous catheter placement is a standard of care in the neonatal intensive care unit. These catheters allow rapid and reliableaccess to the vascular system of critically ill neonates. The umbilical arterial catheter is an ideal line for laboratory monitoring, as well as for invasive blood pressure monitoring. In neonates with an omphalocele, gastroschisis, omphalitis, necrotizing enterocolitis, peritonitis and in neonates undergoing abdominal surgical procedures, a central venous line and/or peripheral arterial line should be provided. (4) Intravenous fluid input in critically ill neonates consists of continuous and controlled intravenous delivery of drugs (such as inotropic agents, vasopressor agents, vasodilators, analgesics, sedatives, insulin, heparin, etc.), parenteral nutrition (PN) and intermittent intravenous drugs (antibiotics, calcium, sodium bicarbonate, etc.). Special infusion pumps, that can regulate fluids and medication at a precision rate of $0.1 \mathrm{~mL} /$ hour or less, should be used for the administration of intravenous fluids. (1) Critically ill neonates often require volume replacement to maintain and/ or restore adequate tissue perfusion. Volume expansion is accomplished by crystalloids, colloids, or various types of blood products.

PN provides energy and nutrients in sufficient quantities to allow normal growth and development. Neonates tolerate PN from day 1 of post-natal life. Electrolyte intake must be adjusted according to the results of regular laboratory analyses performed during the time of PN. (5) Although PN is used widely in the management of critically ill neonates, a swift and smooth transition to enteral feeding is recommended.

Antibiotics are frequently used in critically ill neonates. Newborn infants are especially vulnerable to nosocomial infections because of their intrinsic susceptibility to infection as well as the invasive procedures to which they 


\begin{tabular}{|c|c|c|c|c|}
\hline & $\begin{array}{l}\text { Surgical } \\
\text { neonates } \\
(n=9)\end{array}$ & $\begin{array}{l}\text { Non-surgical } \\
\text { neonates } \\
(\mathrm{n}=21)\end{array}$ & $\begin{array}{l}\text { Together } \\
(n=30)\end{array}$ & $\mathrm{p}$-value \\
\hline Mean birth weight \pm SD & $2539 \pm 868 \mathrm{~g}$ & $2767 \pm 718 \mathrm{~g}$ & $2698 \pm 758 \mathrm{~g}$ & ${ }^{\star} 0.4615$ \\
\hline Mean gestational age \pm SD & $36 \pm 3$ weeks & $36 \pm 3$ weeks & $36 \pm 3$ weeks & *0.8482 \\
\hline Mean ICU stay \pm SD & $14 \pm 10$ days & $6 \pm 3$ days & $9 \pm 7$ days & *0.0017 \\
\hline $\begin{array}{l}\text { No. of patients on mechanical ventilation } \\
\text { (percentage) }\end{array}$ & $8(89 \%)$ & $21(100 \%)$ & $29(97 \%)$ & **0.6614 \\
\hline $\begin{array}{l}\text { No. of patients with central venous catheter } \\
\text { (percentage) }\end{array}$ & $7(78 \%)$ & $3(14 \%)$ & $10(33 \%)$ & $* * 0.0038$ \\
\hline $\begin{array}{l}\text { No. of patients with peripheral arterial line } \\
\text { (percentage) }\end{array}$ & $4(44 \%)$ & $2(10 \%)$ & $6(20 \%)$ & $\star \star 0.0929$ \\
\hline $\begin{array}{l}\text { No. of patients with umbilical venous catheter } \\
\text { (percentage) }\end{array}$ & $4(44 \%)$ & $18(86 \%)$ & $22(73 \%)$ & **0.0615 \\
\hline $\begin{array}{l}\text { No. of patients with umbilical arterial catheter } \\
\text { (percentage) }\end{array}$ & $1(11 \%)$ & 7 (33\%) & $8(27 \%)$ & **0,4200 \\
\hline $\begin{array}{l}\text { No. of patients with percutaneous central } \\
\text { venous silastic catheter (percentage) }\end{array}$ & $2(22 \%)$ & $2(10 \%)$ & $4(13 \%)$ & **0.7291 \\
\hline $\begin{array}{l}\text { No. of patients with urinary catheter } \\
\text { (percentage) }\end{array}$ & $8(89 \%)$ & 19 (91\%) & 27 (90 \%) & $\star \star 0.5960$ \\
\hline
\end{tabular}

ICU, intensive care unit; SD, standard deviation.

* t-test; ${ }^{* *}$ Chi-square test.

are subjected. (6) Some antibiotics have to be diluted according to the pharmaceutical instructions.

During the first weeks of life, blood loss attributable to laboratory testing is acknowledged as the primary factor leading to anaemia in critically ill neonates. (7) Red blood cell (RBC) transfusions are required when $10 \%$ or more of blood volume $(80 \mathrm{~mL} / \mathrm{kg}$ body weight in the full term neonate; $100 \mathrm{~mL} /$ $\mathrm{kg}$ body weight in the preterm neonate) is drawn over 2-3 days or less. (8)

Neonate's kidneys have a limited ability to concentrate urine. Although delayed micturition in a healthy infant is of no concern until after 24 hours postpartum, urine output in a critically ill infant must be assessed after the first 8 to 12 hours of life. Oliguria is defined by urine flow less than $1 \mathrm{~mL} / \mathrm{kg} / \mathrm{h}$. (9) Close monitoring of the urine volume is essential, using urethral catheterization when indicated, or adhesive urine bags and preweighed diapers.

\section{Methods}

We retrospectively evaluated the fluid balance in critically ill neonates admitted to the level III multidisciplinary neonatal and paediatric intensive care unit (ICU) at the University Medical Centre Ljubljana (UMCL), between September 2011 and January 2012. The data on total fluid intake (enteral intake, PN, continuous and intermittent intravenous drug and fluid delivery, and RBC transfusions) and total fluid output (volume of blood samples, urine, drainage) were collected from patient's charts. Neonates were divided into the surgical and non-surgical group. Data were presented as mean \pm standard deviation (SD) or the median with interquartile range (IQR). The independentsamples t-test was used for comparison of normally distributed data and MannWhitney $U$ test for comparison of not normally distributed data. Categorical data were presented as proportions and compared by the Chi-square test. Differences were considered to be statistically significant at a level of $p<$ 0.05 . Statistical analysis was performed using MedCalc statistical software.

\section{Results}

Documentation from 30 critically ill neonates (11 female and 19 male), admitted to the paediatric and neonatal
ICU between September 2011 and January 2012, was evaluated. There were 9 (30\%) surgical and 21 (70 $\%)$ non-surgical patients. Diagnoses in surgical neonates were: caecal perforation 2, arachnoid cyst 1 , oesophageal atresia 1 , gastric perforation 1 , duodenal malrotation 1 , omphalocele 1 , necrotizing enterocolitis 1 and pulmonary atresia 1. Diagnoses in non-surgical neonates were: respiratory distress syndrome 13, apnoeic attacks 2, convulsions 2, meconium aspiration 1 , perinatal asphyxia 1 , haematemesis 1 and bronchopulmonary dysplasia 1. The patients' characteristics are summarized in table 1. All neonates had at least one central catheter or arterial line for blood sampling (table 1).

The mean volume of intravenous fluid intake was $91 \pm 40 \mathrm{~mL} / \mathrm{kg} /$ day and of enteral intake $32 \pm 24 \mathrm{~mL} / \mathrm{kg} /$ day with no statistical differences between groups $(p=0.2753$ and $p=0.1735$ respectively) (figure 1 ).

The mean volume of blood drawn in critically ill neonates in ICU is shown in figure 2A. The mean number of blood samples taken was $3.8 \pm 0.8$ per day $(3.9 \pm 0.5$ per day in surgical and $3.7 \pm$ 

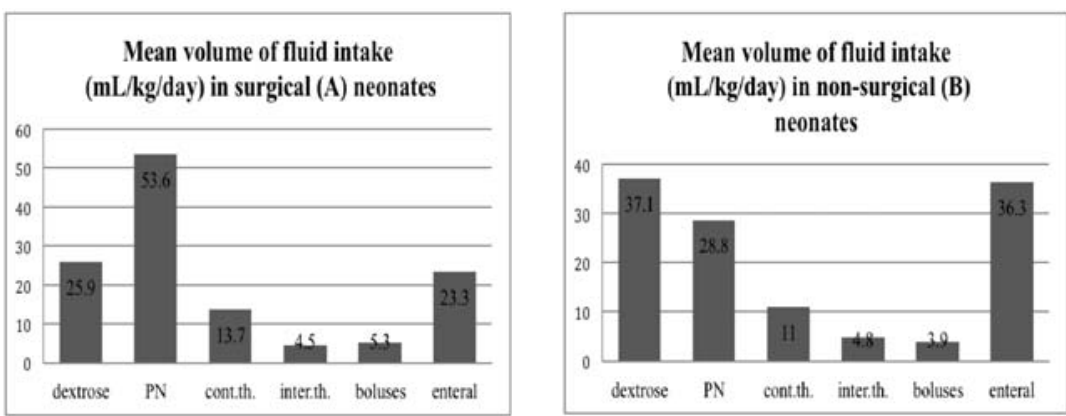

Cont.th., continuous therapy; inter.th., intermittent therapy; PN, parenteral nutrition.

Figure 1. Comparison of total fluid intake in surgical (A) and non-surgical neonates (B).
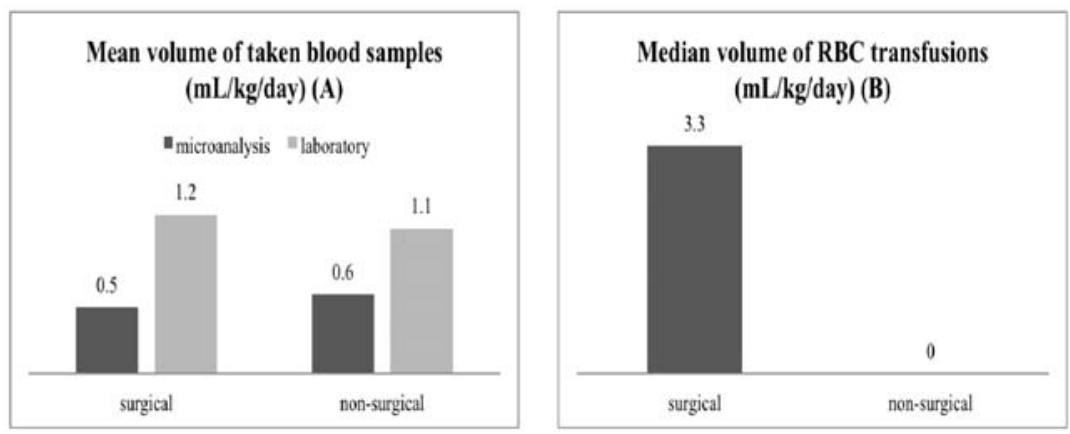

RBC, red blood cell.

Figure 2. Comparison between volume of blood samples taken (A) and RBC transfusions $(B)$ in surgical and non-surgical neonates.
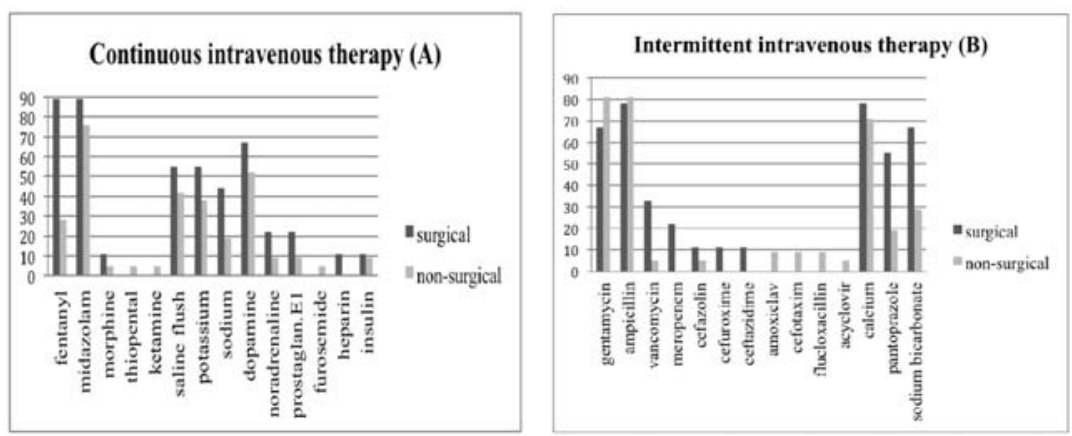

Figure 3. Percentage of continuous (A) and intermittent (B) intravenous therapy in surgical and non-surgical neonates.

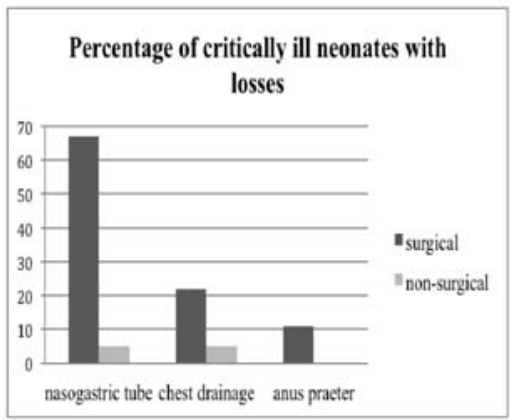

Figure 4. Percentage of surgical and non-surgical neonates with losses via nasogastric tube, chest drainage and anus praeter.
0.8 per day in non-surgical patients with no significant differences between the groups; $p=0.4910$; t-test). Less than one third $(31 \%)$ of blood samples in all patients were taken for microanalysis. As the usual volume of drawn back mixture of fluid and blood from an umbilical arterial or peripheral arterial line is $2.0 \mathrm{~mL}$, before blood sampling, we estimated that approximately one half of it is blood. Consequently, the additional estimated blood loss due to blood sampling from arterial lines was
$3.6 \mathrm{~mL}$ per patient per day in surgical and $3.9 \mathrm{~mL}$ per patient per day in nonsurgical neonates.

Fifty percent of critically ill neonates (78 $\%$ of surgical and $38 \%$ of non-surgical neonates $p=0.1156$; Chi-square test) received 39 units of RBC transfusions, equalling median 8 (33) $\mathrm{mL} / \mathrm{kg}$ of blood per neonate during the study period. Surgical neonates received significantly higher median volume of blood (39 (129) $\mathrm{mL} / \mathrm{kg}$ ) in comparison to non-surgical neonates $(0(20) \mathrm{mL} / \mathrm{kg}) ; p=0.0106$, Mann-Whitney U test (figure 2B)).

Continuous and intermittent intravenous therapy in surgical and non-surgical neonates is shown in figure 3 .

The most frequently used antibiotics in our study were ampicillin and gentamicyn (no statistical differences between the groups; $p=0.7701$, and $p$ $=0.7072$, respectively; Chi-square test). Fentanyl in continuous infusion was more often used in surgical neonates $(p=0.0088$; Chi-square test), while no significant differences were noticed for midazolam and dopamine between the groups $(p=0.7701$, and $p=0.7532$, respectively; Chi-square test).

The mean urine output was $4.7 \pm 1.8$ $\mathrm{mL} / \mathrm{kg} / \mathrm{h}$ with no statistical differences between surgical $(5.1 \pm 1.5 \mathrm{~mL} / \mathrm{kg} / \mathrm{h})$ and non-surgical neonates $(4.5 \pm 1.9 \mathrm{~mL}$ $\mathrm{kg} / \mathrm{h}) ; \mathrm{p}=0.4006$, t-test. The other losses (figure 4) were more often in surgical (78 $\%$ ) than in non-surgical neonates (9\%) (p $=0.0010$; Chi-square test).

\section{Discussion}

Fluid management of critically ill neonates can be improved in several ways. The results of our study showed that fluid balance in neonates in our ICU can be improved by exact calculation of drug dilution, less frequent blood sampling and introduction of closed blood sampling systems.

Critically ill neonates in ICU receive a plethora of medications; both intermittent and in continuous infusions. Several clinical conditions demand that all the medication and alimentation is delivered in a restricted daily volume of fluid. Almost $10 \%$ of all fluid intakes in our patients were delivered in the 
form of continuous medication, among which fentanyl and midazolam were the commonest. Therefore, we should reconsider using less diluted/ more concentrated infusions of these drugs. New infusion pumps provide an opportunity for very precise delivery of the infusion at a rate of $0.01 \mathrm{~mL} / \mathrm{h}$. Furthermore, intermittent intravenous medications (antibiotics, diuretics, antacids, etc...) should be diluted as little as allowed, and pharmaceutical instructions for drug dilution in neonates should be implemented and followed. Diagnostic blood sampling can be restricted and rationalized by avoiding all unnecessary laboratory testing, using combinations of different tests, coordination of laboratory and clinical staff and use of small-volume/ paediatric phlebotomy tubes. The availability of the new bedside, "pointof-care" analysers (I-STAT Abbot, Radiometer Copenhagen ABL 800), that require smaller volumes for blood gas and electrolyte analysis with rapid turn-around times, provides the opportunity to decrease blood loss from phlebotomy and potentially decrease the need for transfusions. (10) In our study less than one third of all blood samples were taken for microanalysis, and patients were submitted to blood sampling almost four times per day. Use of transcutaneous $\mathrm{pO}_{2} / \mathrm{pCO}_{2}$ measurement can reduce the number of blood sampling procedures, particularly during a period when rapid changes in $\mathrm{O}_{2}$ administration or mechanical ventilator settings are taking place. (11)

Blood conservation and consistent sampling are critical for optimal pediatric and neonatal care. (12) Implementing closed blood sampling systems can reduce the need for $\mathrm{RBC}$ transfusions in critically ill neonates. During the sampling process via an open blood sampling system, a small amount of blood is drawn into a "waste" syringe to clear the umbilical/central vessel catheter of infusion fluid, after which the blood sample is taken. In most cases this blood is not returned to the neonate, as it may contain red blood cells that have been damaged by haemolysis or agglutination by contact with the infusion solution. Normal saline is the solution least likely to injure red blood cells. (13) Conversely, closed blood sampling systems include integrated reservoirs, which conserve the precious blood volume of the neonate, and after a clear pure blood sample is drawn for an accurate laboratory analysis, the unused blood and saline are returned to the neonate. In our ICU we usually return the mixture of fluid and blood taken from a central venous catheter, before blood sampling, but not from an arterial line. The results of our study showed that with closed blood sampling systems we were able to salvage $3.6 \mathrm{~mL}$ blood per day per surgical and $3.9 \mathrm{~mL}$ blood per day per non-surgical neonate with an arterial line. On average, during a 1-2 week ICU stay, the volume of thusly conserved blood would amount to the volume of one blood transfusion in a neonate. To avoid this sort of unnecessary blood loss, we are introducing the closed blood sampling systems in our ICU. In conclusion, results of our study show that there are several areas in fluid management in our neonates, which should be reconsidered and improved. Optimization of drug dilution, precise documentation of fluid intake and output, introduction of closed blood sampling systems and less frequent laboratory testing will allow for better fluid management of critically ill neonates.

\section{REFERENCES}

1. Kerr BA, Starbuck AL, Block SM. Fluid and electrolyte management. In: Mernstein GB, Gardner SL, eds. Handbook of Neonatal Intensive Care. 6th ed. St. Louis: Mosby Elsevier; 2006. p. 351-67.

2. Bell EF, Acarregui MJ. Fluid and electrolyte management in the newborn. lowa Neonatology Handbook. 1994 Cited 2013, March 1. Available from: http://www.uichildrens.org/childrens-content.aspx?id=233964

3. Derganc M. Tekočinsko zdravljenje otroka s kirurškim obolenjem. Zdrav Vestn 1980;49:519-23

4. Vorhaben A, Sundelwith RS. Umbilical vein catheterization. In: Shah K, Mason C, eds. Essential Emergency Procedures. Philadelphia: Lippincott Williams \&Wilkins; 2008; 79: p. 374-384.

5. Biesalski HK, Bischoff SC, Boehles HJ, Muehlhoefer A. Water, electrolytes, vitamins and trace elements - Guidelines on parenteral nutrition, Chapter 7. Ger Med Sci 2009; 7: Doc 21.

6. Vergnano S, Sharland M, Kazembe P, Mwansambo C, Heath PT. Neonatal sepsis: an international perspective. Arch Dis Child Fetal Neonatal Ed 2005:90:220-4.

7. Lin JC, Strauss RG, Kulhavy JC, Johnson KJ, Zimmerman MB, Cress GA. Phlebotomy overdraw in the neonatal intensive care nursery. Pediatrics 2000;106:1-6.

8. Lorenz JM. Assessing fluid and electrolyte status in the newborn. Clin Chem 1997;43:205-10.

9. Doherty EG, Simmons CF, Jr. Fluid and electrolyte management. In: Cloherty JP, Eichenwald EC, Stark AR, eds. Manual of Neonatal Care. 6th ed. Philadelphia: Lippincott Williams \&Wilkins; 2008. p. 100-14.

10. Madan A, Kumar R, Adams MM, Benitz WE, Geaghan SM, Widness JA. Reduction in red blood cell transfusions using a bedside analyzer in extremely low birth weight infants. J Perinatol 2005;25:21-5

11. Truog WE, Golombek SG. Principles of Management of Respiratory Problems. In: Avery GB, MacDonald MG, Seshia MMK, eds. Neonatology: Pathophysiology and Management of the Newborn. 6th ed. Philadelphia: Lippincott Williams \&Wilkins; 2005. p. 600-21.

12. Conservation. Safety. Symplicity. Edwards VAMP and VAMP jr. Systems Edwards Lifesciences LLC pamhplet. California, 2002 Cited 2013 March 1 Available from: http://ht.edwards.com/resourcegallery/products/pressuremonitoring/pdfs/vampsystembrochure.pdf

13. Jackson JK, Derleth DP. Effects of various arterial infusion solutions on red blood cells in the newborn. Arch Dis Child Fetal Neonatal Ed 2000;83:130-4. 